\title{
TEORIA DA ESTRUTURA DE PROPRIEDADE: REDES SOCIAIS EM PERIÓDICOS INTERNACIONAIS DE ALTO IMPACTO*
}

\author{
DELCI GRAPEGIA DAL VESCO** \& ILSE MARIA BEUREN**** \\ UNIVERSIDADE REGIONAL DE BLUMENAU - FURB
}

Recibido/ Received/ Recebido: 08/02/2012 - Aceptado/ Accepted/Aprovado: 27/04/2012

\begin{abstract}
Resumo
Este estudo objetiva identificar redes sociais em teoria da estrutura de propriedade nos artigos publicados em periódicos internacionais de alto impacto. Pesquisa sociométrica, com metodologia empírico-analítica, foi realizada em uma perspectiva longitudinal a partir de pesquisa documental. O universo do estudo constitui-se dos periódicos internacionais das áreas de Administração e Contabilidade classificados com índice de alto impacto JCR (Journal Citation Reports) pela ISI Web Knowledge edição 2009. As técnicas de análise utilizadas foram a bibliometria e a análise de redes, em que se compararam as principais características de redes sob o enfoque de small worlds e graus de centralidade. Conclui-se que estas características evidenciam a consolidação do tema como um campo de pesquisa permanente para pesquisadores e contribui para o desenvolvimento da produção científica em estrutura de propriedade, por mensurar aspectos importantes de sua configuração em âmbito internacional.
\end{abstract}

Palavras chave: Bibliometria, sociometria, teoria da estrutura de propriedade, artigos, periódicos internacionais.

\section{TEORÍA DE LA ESTRUCTURA DE PROPIEDAD: REDES SOCIALES EN REVISTAS INTERNACIONALES DE ALTO IMPACTO}

\begin{abstract}
Resumen
El objetivo de este estudio es identificar las redes sociales de la teoría de la estructura de la propiedad en los artículos publicados en las revistas internacionales de alto impacto. Una investigación sociometrica con metodología empírico - analítica fue realizada desde una perspectiva longitudinal de revisión documental. El universo del estudio son las revistas internacionales en las áreas de Administración y Contabilidad clasificados con el índice de alto impacto JCR (Journal Citation Reports) por el ISI Web Knowledge edición 2009. Las técnicas de análisis usadas fueron bibliometría y análisis de las redes sociales, las cuales compararon las características principales de las redes haciendo énfasis en pequeños mundos y grados de centralidad. Se concluyó que estas características muestran la consolidación del tema como un área de investigación permanente para los investigadores y contribuye al desarrollo de literatura científica sobre la estructura de propiedad, ya que mide los aspectos importantes de su configuración a nivel internacional.
\end{abstract}

Palabras clave: Bibliometría, sociometría, teoría de la estructura de propiedad, revistas internacionales.

* Documento preparado na Programa de Pós-Graduação em Ciências Contábeis, Universidade Regional de Blumenau - FURB.

** É doutoranda do Programa de Pós-Graduação em Ciências Contábeis da Universidade Regional de Blumenau - Brasil. Concentra suas pesquisas em estudos relacionados à contabilidade gerencial e controladoria. Blumenau/SC - Brasil, Correo electronico: delcigrape@msn.com

*** Possui doutorado em Controladoria e Contabilidade pela Universidade de São Paulo - Brasil. É professora e coordenadora do Programa de Pós-Graduação em Ciências Contábeis da Universidade Regional de Blumenau - Brasil. Concentra suas pesquisas em estudos relacionados à contabilidade gerencial e controladoria. Blumenau/SC - Brasil. Correo electronico: ilse@furb.br 


\title{
THEORY OF OWNERSHIP STRUCTURE: SOCIAL NETWORKS ON HIGH IMPACT INTERNATIONAL JOURNALS
}

\begin{abstract}
The goal of this study is to identify social networks in the theory of ownership structure in articles published in high impact international journals. Sociometric research with empirical-analytical methodology was performed in a longitudinal perspective from desk research. The universe of the study is the international journals in the areas of Administration and Accounting classified with the index of high impact JCR (Journal Citation Reports) by the ISI Web Knowledge 2009 edition. The techniques of analysis used were bibliometrics and social network analysis, which compared the main characteristics of networks with focus on small worlds and degrees of centrality. It was concluded that these features show the consolidation of the topic as a permanent research field to researchers and contributes to the development of scientific literature on ownership structure, as it measures important aspects of its configuration at international level.

Keywords: Bibliometrics. Sociometry. Theory of Ownership Structure. Articles. International journals.

Dal Vesco, D. \& Beuren, I. (2012) Teoria da estrutura de propriedade: Redes sociais em periódicos internacionais de alto impacto. En: Revista de la Facultad de Ciencias Económicas de la Universidad Militar Nueva Granada. rev.fac.cienc.econ, XX (1)
\end{abstract}

JEL: M40, M49.

\section{Introdução}

Estudos contemporâneos têm sido desenvolvidos a partir do trabalho seminal de Berle \& Means (1932), com a finalidade de pesquisar o impacto no desempenho com a separação entre propriedade e controle. Em 1976, Jensen \& Meckling (1976) desenvolveram a teoria da estrutura de propriedade reunindo três teorias: Teoria dos Direitos de Propriedade, Teoria da Agência e Teoria das Finanças. Os autores afirmam que a teoria da estrutura de propriedade inclui a definição de empresa; a separação entre propriedade e controle e a responsabilidade social de negócios; a determinação de uma estrutura ótima de capital; a especificação do conteúdo dos contratos de crédito; a teoria das organizações; e os laços da oferta na integralização dos problemas mercados.

Jensen \& Meckling (1976) não usam o termo estrutura de capital, porque esse termo geralmente denota a quantidade relativa de títulos, patrimônio, warrants, crédito comercial, que representam o passivo de uma empresa. Os autores usam o termo propriedade para representar que há outra dimensão im- portante para este problema, ou seja, a quantidade relativa de titularidade de créditos detidos pelo insiders (gestão) e outsiders (investidores com nenhum papel direto na gestão da empresa).

Alguns pesquisadores, segundo Chaganti \& Damanpour (1991), principalmente economistas como Larner (1971), Sorensen (1974), McEachern (1975) e Herman (1981), têm distinguido controle de propriedade e a gestão das empresas, e examinaram a relação entre os tipos de propriedade e desempenho. Teóricos organizacionais também investigaram os efeitos de tipos de propriedade sobre estratégia, estrutura e características dos altos executivos (Salancik \& Pfeffer, 1980; Geeraets, 1984; Palmer, Friedland, Jennings \& Powers, 1987).

O campo das finanças, segundo Mendes-da-Silva (2010), carece da identificação de novos caminhos em direção à expansão de suas fronteiras, para além das ferramentas financeiras. Parece também que esses avanços estariam latentes em outras áreas do conhecimento, especialmente aqueles que estão concentrados em entender o comportamento huma- 
no, tais como sociologia, psicologia e antropologia. Assim também se associa essa crítica ao campo da pesquisa em contabilidade.

Contudo, Hesford, Sam Lee, Van Der Stede \& Young (2007) destacam que no âmbito internacional o campo da pesquisa em contabilidade está em expansão desde o início de 1980, devido principalmente: i) o interesse em investigar os fenômenos da contabilidade a partir de várias perspectivas disciplinares (Hopwood, 1978, 1979, 1983; Baiman, 1982, 1990; Cooper, 1983; Macintosh, \& Scapens, 1990; Covaleski, Dirsmith \& Samuel, 1996); ii) o uso de vários métodos (Kaplan, 1984, 1986); iii) o surgimento de novos temas objeto de investigação (Kaplan, 1983, 1993; Johnson \& Kaplan, 1987; Young \& Selto, 1991).

Diante do exposto e focalizado neste estudo, tornase relevante analisar como as pesquisas em estrutura de propriedade estão sendo desenvolvidas, não somente na perspectiva de finanças e contabilidade, mas também sob a configuração da produção cientifica. Sob tal perspectiva, este estudo busca responder a seguinte questão: Como tem se configurada a sociometria da produção científica sobre teoria da estrutura de propriedade em periódicos internacionais na perspectiva de redes sob o enfoque de small worlds e graus de centralidade? Assim, esta pesquisa tem por objetivo identificar redes sociais em teoria da estrutura de propriedade nos artigos publicados em periódicos internacionais de alto impacto.

A relevância da pesquisa está na realização de um estudo bibliométrico e sociométrico sobre teoria da estrutura de propriedade em periódicos internacionais classificados com índice de alto impacto JCR (Journal Citation Reports) pela ISI Web Knowledge nas áreas de Business, Management and Accounting. A contribuição do estudo consiste na sistematização das características das publicações sobre teoria da estrutura de propriedade em âmbito internacional, colaborando para o desenvolvimento da produção científica relativa ao tema.

Este artigo encontra-se estruturado em cinco seções. Na próxima seção, apresenta-se uma breve revisão de literatura sobre teoria da estrutura de propriedade, destacando alguns estudos publicados neste campo. Na terceira seção, definem-se os procedimentos metodológicos adotados para a condução desta pesquisa. Na quarta seção, apresentam-se os resultados da pesquisa, destacando-se os principais autores dos artigos analisados, autores e obras mais citados, redes de coautoria, temas estudados e vertentes teóricas empregadas. Na quinta seção, descrevem-se as considerações finais e recomendações para futuras pesquisas.

\section{Teoria da Estrutura de propiedade}

Embora a teoria da estrutura de propriedade tenha discussões mais amplas e profundas do que os fragmentos expostos nesta seção, apresenta-se brevemente alguns estudos existentes sobre o tema estrutura de propriedade para fundamentar a pesquisa documental objeto de estudo. A relevância da estrutura de propriedade das empresas tem sido bastante explorada na literatura teórica, a qual se focaliza em duas principais dimensões: o grau de concentração e dispersão do capital; e a natureza dos proprietários.

Na medida em que a concentração da propriedade era discutida, Bearle \& Means (1932) apontaram que a separação entre propriedade e controle pode criar conflito de interesses entre os proprietários e gestores. Jensen \& Meckling (1976) reportam que Adam Smith (1776) já afirmava que a negligência e o esbanjamento podem dominar a gestão dos negócios desse tipo de empresas.

Segundo Berle \& Means (1932), dada a participação acionária dispersa, em que os acionistas delegam controle para gestores profissionais, mas não têm os meios ou os incentivos individuais para monitorar suas ações, a gestão tem grande poder e considerável margem de manobra ao exercício das atividades que são benéficas aos agentes às custas dos interesses dos acionistas. Jensen \& Meckling (1976) advertem que os custos de agência aumentam à medida que diminui a maximização dos gestores $e$ a propriedade torna-se mais dispersa. Como apontado por Fama (1980), os sinais fornecidos por um mercado de capitais eficiente sobre o valor dos títulos de uma empresa são susceptíveis de disciplina na gestão da empresa (Iannotta, Giacomo \& Sironi, 2007). 
Quanto à natureza dos proprietários, a hipótese dos direitos de propriedade, conforme Alchian (1965), sugere que as empresas privadas devem realizar a gestão de forma mais eficiente e mais rentável do que as empresas estatais. No caso das empresas estatais, Shleifer \& Vishny (1997) apontam, enquanto são tecnicamente controladas pelo público, são administradas por burocratas que podem pensar que possuem os direitos de controle extremamente concentrados, mas não direitos de fluxo de caixa. Além disso, os burocratas políticos têm metas que estão frequentemente em conflito com a melhoria do bemestar social e são ditados por interesses políticos (Iannotta, Giacomo \& Sironi, 2007).

Demsetz \& Lehn (1985) argumentam que a estrutura de propriedade das empresas varia sistematicamente de modo que seja consistente com a maximização de valor. Grandes corporações de capital aberto apresentam a característica de propriedade difusa, ou seja, separam propriedade e controle nas decisões empresariais. Esta separação figura tanto na teoria econômica da organização como no debate sobre o significado social da corporação moderna. A compreensão de algumas das forças que determinam a estrutura de propriedade das empresas é valiosa, mas também é pertinente para a teoria dos direitos de propriedade.

Segundo Demsetz \& Lehn (1985), o trabalho de Berle \& Means (1932) foi antecipado por Veblen (1924). Veblen acreditava que estava testemunhando a transferência do controle dos proprietários capitalistas para engenheiros gestores, e que as consequências disso fossem articuladas com o crescimento econômico. Na transferência de poder, Veblen via o final dos fins lucrativos (visão capitalista), pois ele acreditava que os proprietários capitalistas não buscavam tanta eficiência e aumento da produção, quanto restrições monopolistas para elevar preços. Neste novo cenário os lucros decorrentes do monopólio seriam sacrificados devido a elevação da eficiência (Demsetz \& Lehn, 1985).

Um dos discípulos de Veblen citados na literatura é Galbraith (1967), o qual argumentou que o controle da propriedade dispersa pelos tecnocratas iria sacrificar o lucro do proprietário para um aumento de produção, o que atenderia os interesses dos con- sumidores (Demsetz \& Lehn, 1985). Para Galbraith (1967), o foco é mais no crescimento da firma do que na maximização dos lucros. Com o controle difuso pelos tecnocratas, o capital deixa de ser fator estratégico de produção e é gradualmente substituído pelo conhecimento tecnológico.

Demsetz \& Lehn (1985) argumentam que, embora os três pontos de vista discutidos sobre as consequências das estruturas de propriedade oferecem diferentes interpretações, implicam numa correlação positiva entre concentração de propriedade e taxa de lucro. Se o controle difuso permite gestores optarem pelas suas necessidades ao invés de cuidar dos lucros dos proprietários, então a empresa mais concentrada apresenta maiores rendimentos e maiores taxas de lucro.

Infere-se do exposto que, da discussão teórica na visão de autores considerados seminais, como Adam Smith (1776), Veblen (1924), Berle \& Means (1932), Jensen \& Meckling (1976), há um ponto em comum relacionado a teoria da estrutura de propriedade, de que a separação entre propriedade e controle geram custos de agencia. Contudo, nem sempre impactam de forma significante no desempenho da empresa, conforme observado no estudo de Demsetz \& Lehn (1985). O que se buscou nesta seção foi construir, a partir desta literatura, um marco analítico para as análises do tópico quatro.

\section{Metodologia}

Pesquisa empírico-analítica foi realizada em uma perspectiva longitudinal a partir de pesquisa documental, conforme descrito por Creswell (1994) e Sampieri, Collado \& Lucio (2006). Para tanto, utilizaram-se as técnicas de análise bibliométrica e redes, em que se compararam as principais características de redes sob o enfoque de small worlds e graus de centralidade. Segundo Macias-Chapula (1998), a pesquisa bibliométrica direciona-se para o estudo dos aspectos quantitativos da produção, disseminação e uso da informação registrada. O estudo sociométrico explora a matriz de relacionamentos estabelecida entre atores sociais, compreendidos neste estudo como autores (Galaskiewicz \& Wasserman, 1994). 
O universo de estudo constitui-se dos periódicos internacionais classificados com índice de alto impacto JCR (Journal Citation Reports) pela ISI Web Knowledge edição 2009, com os artigos disponíveis por meio de acesso eletrônico. Os periódicos listados no JCR com índices de alto impacto foram utilizados pela sua importância na respectiva área de conhecimento. O JCR oferece uma sistemática para avaliar os principais periódicos do mundo, com informações quantificadas, estatísticas com base em dados de citação, ajudando assim a medir a influência da investigação e do impacto do periódico.

Nesta forma de busca identificaram-se onze periódicos: ABACUS - A Journal of Accounting Finance and Business Studies; Accounting and Business Research; Accounting and Finance; Accounting Organizations and Society; Accounting Review; Contemporary Accounting Research; European Accounting Review; Journal of Accounting \& Economics; Journal of Accounting Research; Journal of Business Finance \& Accounting; Review of Accounting Studies. Destes periódicos, cinco foram classificados por Bonner, Hesford, Van Der Stede \& Young (2006) como mais influentes em contabilidade: Accounting, Organizations and Society; Contemporary Accounting Research; Journal of Accounting and Economics, Journal of Accounting Research, and the Accounting Review.

Para a seleção dos artigos nestes periódicos, filtrouse a expressão "Ownership Structure" no título do artigo, por periódico. Nesta pesquisa retornaram 70 artigos, publicados nos seguintes periódicos: Journal Of Banking \& Finance (24 artigos); Accounting And Finance (1); Accounting Review (3); Contemporary Accounting Research (1); European Accounting Review (1); Journal Of Accounting \& Economic (2); Journal of Business Finance \& Accounting (3); Journal of Finance (12); Journal of Financial Economics (18); e Review Of Financial Studies (5 artigos). Nos demais periódicos o retorno foi de zero artigo.

A análise bibliométrica e a análise de redes consubstaciaram-se dos seguintes itens: período de publicação dos artigos; periódico; rede social dividida em quatro períodos; autores mais prolíficos e com maior número de laços; indicadores da rede entre autores; temas dos artigos; quantidade de citações pela base de dados ISI; obras e autores mais citados nos artigos. Ressalta-se que na análise das redes sociais, optou-se pela exploração das redes de coautoria, o que representa uma vertente de análise de redes sociais (Liu, Bollen, Michael \& Van De Sompel, 2005).

Para gerar as figuras representativas da estrutura da rede e seus indicadores empregou-se o software UCI$\mathrm{NET}^{\circledast}$ 6. Para identificar o tema principal dos artigos realizou-se a análise de conteúdo temática conforme preconiza Bardin (2002), particularmente no objetivo $e$ no resumo dos artigos. Como principais fatores limitantes da pesquisa destacam-se a base de busca, que se limitou ao termo "Ownership Structure" no título, e a base de dados, restringida às publicações internacionais classificadas com índice de alto impacto JCR na ISI 2009.

\section{Descrição e análise dos dados}

Nesta seção apresentam-se a descrição e análise dos dados encontrados na pesquisa. Na Tabela 1, destaca-se o número de artigos analisados por periódico e por período.

Nota-se na Tabela 1 uma ampliação, na última década (2002 a 2011), do número de periódicos que publicaram artigos sobre estrutura de propriedade desde 1976, cujo marco foi o trabalho seminal de Jensen \& Meckling (1976), intitulado Theory of Firm: Managerial Behavior, Agency Costs and Ownership Structure, publicado no Journal of Financial Economics. Acompanhando essa tendência, observa-se um crescimento no número de artigos publicados, sendo que o maior número de publicações em um ano (6 artigos) ocorreu naquela década, mais especificamente nos anos de 2006 e 2011. Destacase ainda que o periódico que mais publicou artigos, com 24 publicações sobre o tema, foi o Journal of Banking \& Finance.

Na Tabela 2, apresenta-se o número de coautorias por artigo publicado, mantendo-se a segregação por período.

Nota-se na Tabela 2, que os autores dos artigos analisados dão preferência para publicações em duplas 
Tabela 1. Número de artigos sobre estrutura de propriedade publicados em cada periódico por período

\begin{tabular}{|c|c|c|c|c|c|}
\hline Periódico & 1972_1981 & 1982_1991 & 1992_2001 & 2002_2011 & Total \\
\hline Journal of Banking \& Finance & & 3 & 4 & 17 & 24 \\
\hline Accounting and Finance & & & & 1 & 1 \\
\hline Accounting Review & & 2 & & 1 & 3 \\
\hline Contemporary Accounting Research & & & & 1 & 1 \\
\hline European Accounting Review & & & & 1 & 1 \\
\hline Journal of Accounting \& Economic & & & 1 & 1 & 2 \\
\hline Journal of Business Finance \& Accounting & & & & 3 & 3 \\
\hline Journal of Finance & & 4 & 6 & 2 & 12 \\
\hline Journal of Financial Economics & 1 & 6 & 9 & 2 & 18 \\
\hline Review of Financial Studies & & & 2 & 3 & 5 \\
\hline Total & $1(1,43 \%)$ & $15(21,43 \%)$ & $22(31,43 \%)$ & $32(45,71 \%)$ & 70 \\
\hline
\end{tabular}

Tabela 2. Número de coautorias por artigo²

\begin{tabular}{|c|c|c|c|c|c|}
\hline Período & 1 Autor & 2 Autor & 3 Autor & > 3 Autor & Total \\
\hline \multirow{2}{*}{$1972 \_1981$} & & 1 & & & 1 \\
\cline { 2 - 6 } & & $100 \%$ & & & $1,43 \%$ \\
\hline \multirow{2}{*}{$1982 \_1991$} & 4 & 7 & 3 & 1 & 15 \\
\cline { 2 - 6 } & $27 \%$ & $47 \%$ & $20 \%$ & $7 \%$ & $21,43 \%$ \\
\hline \multirow{2}{*}{$1992 \_2001$} & 9 & 10 & 3 & & 22 \\
\cline { 2 - 6 } & $41 \%$ & $45 \%$ & $14 \%$ & $0 \%$ & $31,43 \%$ \\
\hline \multirow{2}{*}{$2002 \_2011$} & 11 & 12 & 7 & 2 & 32 \\
\cline { 2 - 6 } & $34 \%$ & $38 \%$ & $22 \%$ & $6 \%$ & $45,71 \%$ \\
\hline \multirow{2}{*}{ Total } & $\mathbf{2 4}$ & $\mathbf{3 0}$ & $\mathbf{1 3}$ & $\mathbf{3}$ & $\mathbf{7 0}$ \\
\cline { 2 - 6 } & $\mathbf{3 4 \%}$ & $\mathbf{4 3 \%}$ & $\mathbf{1 9 \%}$ & $\mathbf{4 \%}$ & $\mathbf{1 0 0 \%}$ \\
\hline
\end{tabular}

e independentes. Observa-se também, que há apenas três artigos publicados em cooperação que apresentam mais de 3 autores.

A Figura 1 ilustra as redes de coautoria por período. Cada nó representa uma publicação, cujos laços expressam relações de autoria. Neste estudo, os nós são interpretados como pesquisadores que gastam tempo escrevendo artigos. A produtividade de cada nó é uma função de suas ligações. Um laço representa uma colaboração entre dois pesquisadores. $\mathrm{O}$ tempo que um pesquisador gasta em um determinado projeto é inversamente proporcional ao número de projetos que o pesquisador está envolvido (Jackson \& Wolinsky, 1996).

Observa-se na Figura 1, que nas décadas anteriores a 2001 as redes se restringiam a díades, sendo que, 
Figura 1. Rede de coautoria por período 3

1972-1981

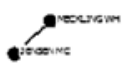

1982-1991

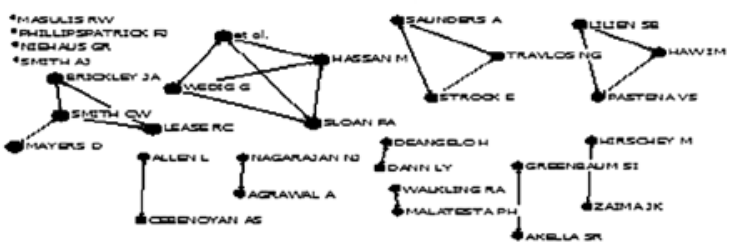

1992-2001

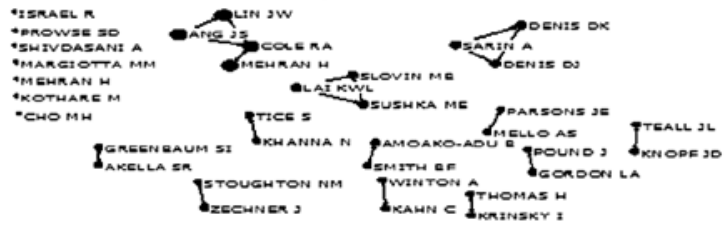

no período de 1972 a 1981, ocorreu apenas um laço entre os autores Jensen \& Meckling (1976). Contudo, pela análise das citações nota-se que esse trabalho teve alto impacto na produção científica. Além do pequeno número de publicações sobre estrutura de propriedade até 2001 , tem-se também que os autores optaram por publicações individuais ou parcerias entre no máximo dois autores, e em poucos casos parcerias acima de dois autores.

Portanto, a rede de coautoria caracteriza-se por sua fragmentação em díades e tríades. Há predominância de laços fortes, com ausência de grupos conectados entre si. Contudo, o fato dos pesquisadores formarem uma rede coesa pode caracterizar, apesar de não se poder fazer maiores inferências, mínimas trocas de informações, de modo a caracterizar pouca potencialidade de formação de capital social na rede (Burt, 1992).

Verifica-se, assim, a ausência de lacunas estruturais, as quais, de acordo com Burt (1980; 1992), forne- cem uma vantagem competitiva para o indivíduo que realiza a conexão, uma vez que esse usufrui de acesso às informações dos autores. Esse indivíduo também pode conquistar poder de agenciamento de contato entre os autores aos quais se encontra vinculado.

Em decorrência de maior concentração de publicações no último período (2002 a 2011), as relações entre os seus autores são exibidas em separado na Figura 2.

Figura 2. Rede de coautoria entre autores no período de 2002-20114

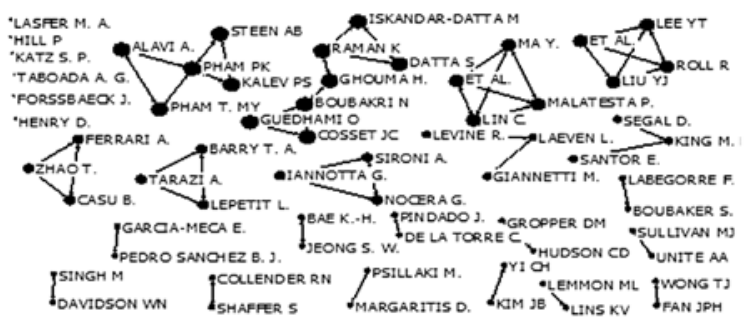

Na última década (2002-2011), observa-se uma ampliação mais considerável nas relações. Amplia-se o número de redes e de autores envolvidos nas redes, sendo que o componente principal apresentou 7 autores, no qual se tem o autor Ghouma estabelecendo ponte entre os outros dois componentes. Esta ampliação nas redes acompanha o crescimento no número de publicações sobre o tema, mais intenso na última década.

Neste período, observam-se principalmente redes formadas por laços fortes, exceto pelas duas tríades, nas quais os autores Laeven e King conectam dois autores que sem eles estariam isolados. Essa estrutura corresponde ao que Granovetter (1973) define como laço fraco, ou seja, contatos indiretos formados por meio de pontes, possibilitando maior inovação.

Nota-se que a rede naquela década se restringiu a produções individuais, díades e tríades, duas redes

Fonte: dados da pesquisa.

4 Fonte: dados da pesquisa. 
estreladas e dois componentes principais. Isso mostra a predominância de bipolarização da produção cientifica evidenciada pela existência de dois componentes, dentro dos componentes dos quais fazem parte. Também mostra uma predominância de laços fracos.

$\mathrm{Na}$ Tabela 3, exibem-se os autores com mais artigos publicados e com mais laços de cooperação, no período de 1972 a 2011.
Observa-se, na Tabela 3, que o autor com maior número de laços foi Pham, P.K. com 6 laços e duas publicações. Por outro lado, têm-se autores com uma única publicação e quatro laços de cooperação. $\mathrm{O}$ que caracteriza um baixo grau prolífico da produção. Ou seja, autores publicaram um único trabalho sobre o tema estrutura de propriedade ao longo de quatro décadas de pesquisa. Vale lembrar que a base de busca limitou-se ao termo "Ownership Structure" no título.

Tabela 3. Autores mais prolíficos e com maior número de laços ${ }^{7}$

\begin{tabular}{|l|c|c|c|l|c|c|c|}
\hline Autor & Artigos & Laços & Participação & \multicolumn{1}{|c|}{ Autor } & Artigos & Laços & Participação \\
\hline Pham. P. K. & 2 & 6 & $1,89 \%$ & Liu, Y.J. & 1 & 4 & $1,26 \%$ \\
\hline Boubakri, N. & 2 & 5 & $1,58 \%$ & Ma, Y. & 1 & 4 & $1,26 \%$ \\
\hline Cole, R. A. & 2 & 5 & $1,58 \%$ & Malatesta, P. & 1 & 4 & $1,26 \%$ \\
\hline Denis, D. J. & 2 & 5 & $1,58 \%$ & Raman, K. & 1 & 4 & $1,26 \%$ \\
\hline Sarin, A. & 2 & 5 & $1,58 \%$ & Roll, R. & 1 & 4 & $1,26 \%$ \\
\hline Smith C. W. & 2 & 5 & $1,58 \%$ & Sloan, F.A. & 1 & 4 & $1,26 \%$ \\
\hline Akella, S. R. & 2 & 4 & $1,26 \%$ & Wedig, G. & 1 & 4 & $1,26 \%$ \\
\hline Greenbaum, S. I. & 2 & 4 & $1,26 \%$ & Alavi, A. & 1 & 3 & $0,95 \%$ \\
\hline Hassan, M. & 1 & 4 & $1,26 \%$ & Ang, J.S. & 1 & 3 & $0,95 \%$ \\
\hline King, M. R. & 2 & 4 & $1,26 \%$ & Barry, T.A. & 1 & 3 & $0,95 \%$ \\
\hline Laeven, L. & 2 & 4 & $1,26 \%$ & Brickley, J.A. & 1 & 3 & $0,95 \%$ \\
\hline Lee, Y.T. & 1 & 4 & $1,26 \%$ & Casu, B. & 1 & 3 & $0,95 \%$ \\
\hline Lin, C. & 1 & 4 & $1,26 \%$ & Cosset, J.C. & 1 & 3 & $0,95 \%$ \\
\hline
\end{tabular}

A Tabela 4 exibe os indicadores relacionados à rede de cooperação entre autores, por período.

Verifica-se na Tabela 4, que no período pesquisado (1972 a 2011) identificaram-se 70 artigos publicados sobre o tema e 132 pesquisadores/autores. Isso evidencia crescimento tanto no número de artigos como de pesquisadores, com destaque para o período inicial (1972-1981) de 2 laços e o final (20022011) de 102 laços. A média de colaboração foi de 1,56 laços por pesquisador no período final.
Contudo, destaque-se que no período de 1992-2001 houve uma queda nesse indicador em relação à década anterior, o que caracteriza, nesse período, que os pesquisadores preferiram publicar isoladamente. Nota-se que no período de 1992 a 2001 ocorreram 7 unidades isoladas, com um total de 35 pesquisadores, que representa $20 \%$ de isolados. Já para o período de 2002 a 2011 esse percentual caiu para 9\%.

A Figura 3 mostra os componentes principais da rede e os respectivos períodos de publicação dos artigos.

7 Fonte: dados da pesquisa. 
Tabela 4. Indicadores da rede de cooperação entre autores por período ${ }^{8}$

\begin{tabular}{|l|c|c|c|c|}
\hline \multicolumn{1}{|c|}{ Descrição } & $\mathbf{1 9 7 2 - 1 9 8 1}$ & $\mathbf{1 9 8 2 - 1 9 9 1}$ & $\mathbf{1 9 9 2 - 2 0 0 1}$ & $\mathbf{2 0 0 2 - 2 0 1 1}$ \\
\hline Número de artigos & 1 & 15 & 22 & 32 \\
\hline Pesquisadores (n) & 2 & 30 & 35 & 65 \\
\hline Dados Observados_Rede & $1972-1981$ & $1982-1991$ & $1992-2001$ & $2002-2011$ \\
\hline Laços & 2 & 44 & 40 & 102 \\
\hline Número médio laços da rede (k) & 1,000 & 1,467 & 1,143 & 1,569 \\
\hline Numero de componentes & 1 & 14 & 19 & 27 \\
\hline Tamanho Componente Principal & 1 & 4 & 4 & 7 \\
\hline Tamanho 20. maior componente & 0 & 4 & 3 & 5 \\
\hline Unidades Isoladas & 0 & 4 & 7 & 6 \\
\hline Densidade & 1,000 & 0,699 & 0,247 & 0,158 \\
\hline Centralização & $0,00 \%$ & $5,67 \%$ & $2,90 \%$ & $3,92 \%$ \\
\hline Distância média & 1,000 & 1,083 & 1,095 & 1,443 \\
\hline Coeficiente de agrupamento & 1,000 & 0,949 & 1,037 & 0,839 \\
\hline Dados Aleatórios & $1972-1981$ & $1982-1991$ & $1992-2001$ & $2002-2011$ \\
\hline Coeficiente de agrupamento rede esperado \\
(k/n) & 0,50 & 0,05 & 0,03 & 0,02 \\
\hline PL: Distância Média Esperada [In(n)/In(k)] & 1,00 & 8,88 & 26,60 & 9,27 \\
\hline Indicadores & $1972-1981$ & $1982-1991$ & $1992-2001$ & $2002-2011$ \\
\hline PL taxa (PL real / PL aleatório) & 1,00 & 0,12 & 0,04 & 0,16 \\
\hline CC taxa (CC real / CC aleatório) & 2,00 & 19,41 & 31,75 & 34,76 \\
\hline Q: Coef. Small World (CC taxa/ PL taxa) & 2,00 & 159,04 & 771,40 & 223,23 \\
\hline
\end{tabular}

Figura 3. Rede de coautoria entre autores - Componentes principais ${ }^{9}$

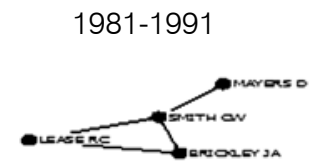

$1992-2001$

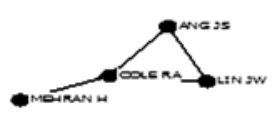

2002-2011

\section{$1^{\circ}$. Componente}

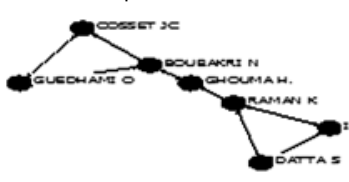

$2^{\circ}$. Componente

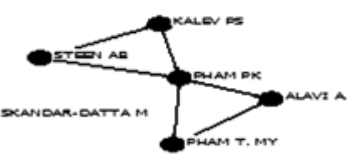

Verifica-se na Tabela 4, que a densidade da rede foi de 1 no período 1972-1981; de 0,699 no período 1982-1991; de 0,247 no período 1992-2011; e de 0,158 no período 2002-2011. Neste caso, a possibilidade média de um determinado ator estar ligado a outro foi baixa. Característica também observada nos estudos de Lazzarini (2007), Rossoni \& Guarido Filho (2009), Dal Vesco, Santos \& Scarpin (2010) e Fernandes, Dal Vesco e Walter (2011). O coeficiente de agrupamento ficou entre 0,839 e 1,037, considerado alto quando comparado ao esperado, que foi de 0,002 a 0,5 para a quantidade de artigos analisados, o que indica a existência de grupos coesos, apesar de pequenos.

Observa-se ainda que nos períodos iniciais agruparam o componente principal 4 pesquisadores/ autores, e no período final (2002-2011) além do componente principal, com 7 participantes, como já

\footnotetext{
8 Fonte: dados da pesquisa.

9 Fonte: dados da pesquisa.
} 
mencionado, no qual o autor central é Ghouma, há também outro componente de 5 autores. Nesse caso os componentes não interagem entre si.

Os pesquisadores do tema estrutura de propriedade dos artigos analisados mostram estarem estruturalmente próximos um dos outros. Por exemplo, levando em consideração a distância média entre os pesquisadores no componente principal, é observado que eles necessitam, em média, de somente 1 a 1,4 intermediários para alcançar qualquer pesquisador dentro do próprio componente. Tal configuração das relações, alinhada ao elevado coeficiente de agrupamento (entre 0,8 a 1,037, próximos de 1) indica a ocorrência de agrupamentos com maior densidade nas relações. Fatores que podem explicar tal comportamento são a imersão institucional e a localidade dos pesquisadores. Tal também foi observado nas análises de Rossoni \& Graeml (2009), para a área de Administração da Informação no Brasil.

Pelas premissas apontadas no modelo de Watts \& Strogatz (1998), que identificam baixa densidade total, densidade local muito superior e distância média similar, como características de redes do tipo mundos pequenos, a rede analisada se apresenta estruturada como um small world.

Na Tabela 5, apresenta-se o número de citações por artigo publicado. Optou-se por elencar os artigos acima de 100 citações. Destaca-se que dos 70 artigos da amostra, 7 ainda não foram citados. Desses 7 artigos, 5 foram publicados em 2011, 1 em 2009 e 1 em 1995. Este último foi produzido por Margiotta, sob o título Executive-Compensation And Corporate-Ownership Structure-An Empirical-Analysis.

$\mathrm{Na}$ Tabela 5, destaca-se que o primeiro artigo sobre estrutura de propriedade, de Jensen \& Meckling, (1976), pela base de dados da ISI, atingiu 6.479 citações, considerado seminal. Na década de 80 dois artigos tiverem destaque em citações, um de autoria de Brickley, Lease \& Smith, (1988), com 257 citações, e outro com 116, de autoria de Malatesta $\&$ Walkling (1988), em que relacionaram Poison pill aos títulos com riqueza do acionista, lucratividade com estrutura de propriedade. Nos anos 90 merecem destaque, com 239 citações, o artigo de Me-

Tabela 5. Quantidade de citações por artigo ${ }^{10}$

\begin{tabular}{|c|c|c|c|}
\hline Título & Autor & Ano & Qt. Citações \\
\hline Theory of Firm: Managerial Behavior, Agency Costs and Ownership Structure & Jensen MC ; Meckling WH & 1976 & 6479 \\
\hline Ownership structure and voting on antitakeover amendments & Brickley, J.A.; Lease, R.C.; Smith, C.W. & 1988 & 257 \\
\hline Executive-compensation structure, ownership, and firm performance & Mehran, $\mathrm{H}$. & 1995 & 239 \\
\hline Ownership structure, investment, and the corporate value: an empirical analysis & Cho, M.H. & 1998 & 160 \\
\hline Board composition, ownership structure, and hostile takeovers & Shivdasani, A. & 1993 & 152 \\
\hline Poison pill securities: stockholder wealth, profitability, and ownership structure & Malatesta, P.H.; Walkling, R.A. & 1988 & 116 \\
\hline $\begin{array}{l}\text { Ownership structure, corporate governance, and firm value: evidence from the } \\
\text { east Asian financial crisis }\end{array}$ & Lemmon, M.L.; Lins, K.V. & 2003 & 116 \\
\hline $\begin{array}{l}\text { Corporate ownership structure and the informativeness of accounting earnings } \\
\text { in east Asia }\end{array}$ & Fan, J.P.H.; Wong, T.J. & 2002 & 114 \\
\hline Agency costs and ownership structure & Ang, J.S.; Cole, R.A.; Lin, J.W. & 2000 & 111 \\
\hline Ownership structure, deregulation, and bank risk-taking & Saunders, A.; Strock, E.; Travlos, N.G. & 1990 & 109 \\
\hline Ownership structure and top executive turnover & Denis, D.J.; Denis, D.K.; Sarin, A. & 1997 & 108 \\
\hline
\end{tabular}

10 Fonte: dados da pesquisa. 
hran (1995), sobre tema remuneração de executivos e desempenho empresarial associado à estrutura de propriedade, e com 108 publicações, o artigo de Denis, Denis \& Sarin (1997).

Figura 4. Rede de temas por período ${ }^{11}$
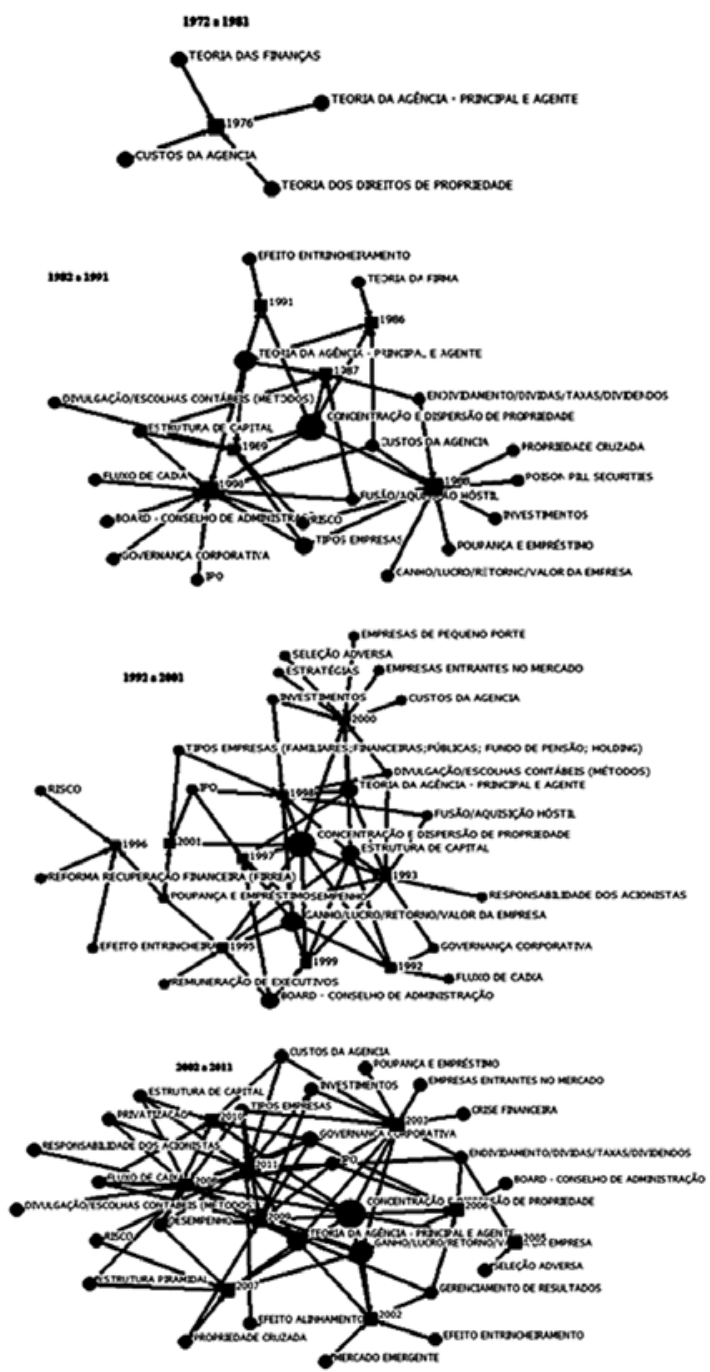

Na Figura 4 e Tabela 6, destaca-se o resultado da análise temática. Além dos temas apresentados nesta tabela foram identificados mais 10 (crise financeira; empresas de pequeno porte; estratégias; merca- do emergente; poison pill securities; remuneração de executivos, reforma e recuperação financeira (FIRREA); teoria da firma; teoria das finanças; teoria dos direitos de propriedade), explorados em um artigo cada.

Na Figura 4 mostra-se a evolução temática nos períodos. Cabe destacar que os temas recorrentes foram concentração/dispersão de propriedade, os quais desde 1982 foram objeto de pesquisa e recorrentes durante três décadas, e Teoria da Agencia. A partir de 1982, o segundo tema mais pesquisado, recorrente por duas décadas, foi Ganho/Lucro/ Retorno/Valor da Empresa, o qual tem relação com estrutura de propriedade e desempenho. Alguns temas emergentes que surgiram na última década de análise entre 2002 a 2011 foram gerenciamento de resultados, privatizações, crise financeira. Também apresenta-se como importante objeto de análise o tema governança corporativa, o qual surgiu pela primeira vez em 1992 e 1993 e após uma década apresenta-se como um tema emergente e recorrente até 2011.

Cabe destaque aos temas teoria da firma, teoria das finanças, teoria dos direitos de propriedade desenvolvidos do trabalho seminal de Jensen \& Meckling (1976), que após sua publicação foi base de estudo de 21 artigos com o tema Teoria da Agencia e 11 em Custos de Agencia. Jensen \& Meckling (1976) integram elementos da teoria da agência, da teoria dos direitos de propriedade e da teoria das finanças para desenvolver uma teoria da estrutura de propriedade da empresa, definem o conceito de custos de agência, e sua relação com a separação de propriedade.

Nota-se na Tabela 6, que o tema mais recorrente nos artigos analisados é o relacionado à concentração $e$ dispersão de propriedade, no qual estão incluídos aspectos da separação entre propriedade e controle, proposta inicialmente por Berle \& Means (1932) e Jensen \& Meckling (1976). Estrutura de propriedade pode ser definida em duas dimensões principais. Primeira, pelo grau de concentração da propriedade: as empresas podem ser diferentes, porque a sua

11 Fonte: dados da pesquisa. 
Tabela 6. Temas dos artigos ${ }^{12}$

\begin{tabular}{|l|c|l|l|c|}
\hline \multicolumn{1}{|c|}{ Tema } & Artigos & & \multicolumn{1}{c|}{ Tema } & Artigos \\
\hline Concentração dispersão de propriedade & 43 & & Poupança e Empréstimo & 6 \\
\hline Teoria da Agência - Principal Agente & 21 & & Risco & 5 \\
\hline Ganho/Lucro/Retorno/Valor da Empresa & 20 & & Fluxo de Caixa & 5 \\
\hline Estrutura de Capital & 14 & & Fusão/Aquisição Hostil & 3 \\
\hline $\begin{array}{l}\text { Tipo de Empresa(Familiares;Financeiras;Públicas; } \\
\text { Fundo De Pensão; Holding) }\end{array}$ & 13 & & Efeito entrincheiramento & 3 \\
\hline Desempenho & 12 & & Gerenciamento de resultados & 3 \\
\hline IP0 & 12 & & Privatização & 3 \\
\hline Custos da agencia & 11 & & Propriedade cruzada & 2 \\
\hline Governança corporativa & 11 & & Efeito alinhamento & 2 \\
\hline BoARD - Conselho De Administração & 8 & & Empresas entrantes no mercado & 2 \\
\hline Endividamento/dividas/taxas/dividendos & 8 & & Estrutura piramidal & 2 \\
\hline Divulgação/escolhas contábeis (métodos) & 6 & & Responsabilidade dos acionistas & 2 \\
\hline Investimentos & 6 & & Seleção adversa & 2 \\
\hline
\end{tabular}

propriedade é mais ou menos dispersa. Segunda, pela natureza dos proprietários: dado o mesmo grau de concentração, duas empresas podem ser diferentes se o governo detém participação em uma delas (maioria); do mesmo modo, uma empresa com o capital disperso é diferente de uma empresa comum (Iannotta, Giacomo \& Sironi, 2007).

Na sequência, com 21 artigos tem-se teoria da agência - principal e agente. Relacionado a essa temática tem-se o tema Custos da Agencia com 11 artigos. Assim, da soma do tema teoria e custos da agencia, há 32 observações com essa temática. Jensen \& Meckling (1976) definem a relação principal-agente como "um contrato em que uma ou mais pessoas (o principal) delega à outra pessoa (o agente) a execução de algum serviço em seu nome, que envolve delegar alguma autoridade de tomada de decisão para o agente".

O terceiro tema mais investigado está relacionado aos impactos da estrutura de propriedade nos Ganhos/Lucros/Retorno/Valor da Empresa. Os artigos relacionam uma dessas variáveis à estrutura de pro- priedade, por meio de estudos empíricos, testando hipóteses. Nesta mesma metodologia de pesquisa, os temas Desempenho e IPO também são variáveis que foram relacionadas à estrutura de propriedade.

Como quarto tema mais recorrente identificou-se a Estrutura de Capital, que se refere à forma de combinação entre recursos próprios ou de terceiros pelas empresas, no sentido de viabilizar seus investimentos. Damodaran (2002) considera que dívida e patrimônio podem afetar tanto a taxa de corte quanto os fluxos de caixa. O tipo de financiamento escolhido necessita ser o mais próximo possível do ativo a ser financiado. Nesta perspectiva, ocupando a $8^{\mathrm{a}}$ posição, o tema endividamento, dívidas, taxas, dividendos apresentou 11 observações.

$\mathrm{Na}$ quinta colocação entre os temas mais empregados têm-se tipos de empresas, que versaram de forma especifica sobre os seguintes tipos: familiares, financeiras, públicas, fundo de pensão, holding. De forma geral, as pesquisas desenvolvidas nesse contexto tiveram como objeto os diferentes tipos de empresas, relacionando-os à estrutura de propriedade.

12 Fonte: dados da pesquisa. 
Como sexto tema tem-se governança corporativa, que discute o comportamento dos gestores e os níveis de governança corporativa vinculados ao tipo de estrutura de propriedade das empresas. A maior parte sobre governança corporativa examina os problemas de agência que surgem a partir de duas estruturas de propriedade: (i) $100 \%$ acionistas minoritários; ou (ii) um proprietário, grande controle combinado com acionistas minoritários (Shleifer \& Vishny, 1997). Dennis \& McConnell (2003) definem governança corporativa como "o conjunto de mecanismos que mantêm um equilibrio adequado entre os direitos dos acionistas $e$ as necessidades do conselho de administração e gestão para dirigir e gerir os negócios da empresa". Depreende-se que os mecanismos de governança corporativa podem ajudar a resolver os dois conjuntos de conflitos: entre proprietários e gestores, e entre acionistas controladores $e$ acionistas minoritários.

Na oitava colocação entre os temas mais empregados tem-se Board - Conselho de Administração e Endividamento, dívidas, taxas e dividendos, este já citado. Aquele versa sobre a composição do conselho de administração e sua ligação com estrutura de propriedade. Estudos recentes destacam a importância de diretores externos. Mayers, Shivdasani \& Smith Jr. (1997) investigaram o papel de diretores externos no processo de controle corporativo por meio da exploração e variação na propriedade; Weisbach (1988) examinaram a rotatividade de CEOs; Shivdasani (1993) analisaram se as diferenças na estrutura do conselho de administração e participação acionária contribuem para a incidência de aquisições hostis; Brickley, Coles \& Terry (1994) verificaram a adoção de poison pill; e Cotter, Shivdasaniand \& Zenner (1997) identificaram os retornos aos acionistas.

Em posições de menores ocorrências, na $10^{\mathrm{a}}$ e $11^{\mathrm{a}}$ posições, merecem destaque os temas: Efeito entrincheiramento, Gerenciamento de resultados, Propriedade cruzada, Efeito alinhamento, Estrutura piramidal. O efeito entrincheiramento inclui expropriação pura e simples, ou seja, o acionista controlador beneficia-se de self-dealing, transações em que lucros são transferidos para outras empresas que ele controla. O acionista controlador também pode exercer expropriação em troca de utilidades pessoais. $\mathrm{O}$ proble- ma entrincheiramento criado pelo controle proprietário é semelhante ao problema entrincheiramento gerencial discutido por Morck, Shleifer \& Vishiny (1988). Por outro lado tem-se o efeito alinhamento, considerado uma forma de mitigar o problema do entrincheiramento, aumentando mais a participação do acionista controlador na propriedade. Assim, a concentração da propriedade tem um incentivo ao efeito de alinhamento: aumentar as participações na propriedade de um proprietário além do nível mínimo necessário para o controle eficaz, melhorando o alinhamento de interesses entre o controle proprietário e os acionistas minoritários e reduzindo os efeitos de entrincheiramento (Fan \& Wong, 2002).

Em relação ao tema gerenciamento de resultados relacionado aos estudos de estrutura de propriedade, tem-se da literatura que diferenças na concentração da estrutura de propriedade das empresas podem afetar os incentivos, os relatórios e o gerenciamento de resultados (Katz, 2009). Porque em uma estrutura de propriedade mais concentrada, grandes proprietários normalmente são diretamente envolvidos na gestão da empresa, comunicando o desempenho da empresa por meio de demonstrações financeiras $e$, portanto, pode ocorrer gerenciamento de resultados (Leuz, 2006).

O tema propriedade cruzada ocupou a $11^{\mathrm{a}}$ posição. Sua principal característica ocorre quando a propriedade de duas ou mais empresas entre elas dificulta a perda do controle. Nesses casos, os acionistas mantêm o controle da empresa com menor posse direta de ações. A estrutura piramidal ocupou a $10^{\mathrm{a}}$ posição. $\mathrm{O}$ efeito pirâmide, caracteriza-se quando a última estrutura da empresa pertence a uma cadeia com participações uma nas outras (Shleifer \& Vishny, 1997).

A partir da catalogação das 2.492 referências inventariadas nos 70 artigos publicados sobre o tema estrutura de propriedade, foi possível identificar os autores mais citados na literatura internacional. Para tanto, fez-se a contagem de frequência individual para cada autor, nesse cálculo foram desconsideradas as co-autorias ou autorias múltiplas. Esta classificação apontou o ranking dos 10 autores com maior frequência de citações e de referências. A Tabela 7 
apresenta os dez autores mais referenciados nos artigos, o número de vezes que os autores foram citados no corpo do texto e a quantidade de obras (neste artigo obras compreendem não somente livros, mas todas as pesquisas publicadas em livros, artigos e outros). Além dos autores indicados na Tabela 7, mais 370 foram referenciados ao menos uma vez nos artigos. O número mínimo e máximo ficou entre 1 a 15 referências para os não inclusos no ranking.

Observa-se na Tabela 7, que as obras mais citadas e referenciadas nos artigos analisados são as de Jensen, $1^{\mathrm{a}}$ colocação em quantidade de citações e de referências; Shleifer, $2^{\mathrm{a}}$. colocação em citações; e La Porta, $2^{a}$ colocação em referências.

Jensen produziu vários artigos em parceria, sendo que a obra com maior ocorrência foi produzida juntamente com Meckling, em 1976. Jensen produziu com outros co-autores, tais como: Jensen \& Ruback (1983); Fama \& Jensen (1983); Jensen \& Warner (1988); Jensen \& Murphy (1990a). De forma individual destacam-se Jensen (1969; 1979; 1986; 1993). Além desses, há mais 17 artigos. Entre todos, o mais referenciado foi Jensen \& Meckling (1976). E em segundo ocorreu um empate, com 5 ocorrências cada, entre a obra produzida em conjunto com Ruback
(Jensen \& Ruback,1983), sob o título de The market for corporate control; e a produzida em co-autoria com Murphy (Jensen \& Murphy, 1990b), intitulada de CEO incentives: It's not how much you pay, but how. Ambas em Teoria da Agência - Principal Agente.

Meckling, entre os 70 artigos selecionados, foi referenciado somente em uma obra, citado pelos referidos autores. A produção foi individual de Meckling (1976), sob o título de Values and the Choice of the Model of the Individual in the Social Sciences. Neste artigo o autor compara criticamente os modelos de homem propostos na literatura das ciências sociais e os reconhece como distintos. Defende que o modelo mais frutífero seria o Resourceful, Evaluative, Maximizing Model (REMM), o qual reconhece no homem três atributos básicos: o homem é Versátil, ele analisa as razões e as consequências das mudanças no seu ambiente e em seu próprio comportamento; é um Avaliador, ele tem preferências; e, finalmente, é um Maximizer, ele age de modo a alcançar a maximização dos objetivos, ou seja, o que percebe como nível bom. O autor Discute ainda três modelos de homem: sociológico, psicológico e político. Argumenta que o modelo do indivíduo (REMM) fornece promissora base para uma abordagem unificada à ciência das organizações.

Tabela 7. Autores mais citados (referenciados) ${ }^{13}$

\begin{tabular}{|c|c|c|c|c|c|c|c|}
\hline \multirow{2}{*}{ Autor } & \multicolumn{2}{|c|}{ Citações } & \multicolumn{2}{|c|}{ Referências } & \multirow{2}{*}{$\begin{array}{l}\text { Distintas Obras } \\
\text { Citadas }\end{array}$} & \multirow{2}{*}{$\begin{array}{l}\text { Relação entre Ci- } \\
\text { tações e Obras }\end{array}$} & \multirow{2}{*}{$\begin{array}{c}\text { Relação entre Citações e } \\
\text { Referências }\end{array}$} \\
\hline & Qtde. & Ranking & Qtde. & Ranking & & & \\
\hline Jensen & 218 & $1 \mathrm{a}$. & 69 & $1 \mathrm{a}$. & 18 & 12,11 & 3,16 \\
\hline Shleifer & 192 & 2a. & 39 & $4 a$. & 8 & 24 & 4,92 \\
\hline Claessens & 120 & $3 a$. & 29 & $6 a$. & 7 & 17,14 & 4,14 \\
\hline La Porta & 114 & 4a. & 45 & $2 a$. & 11 & 10,36 & 2,53 \\
\hline Demsetz & 106 & $5 a$. & 42 & 3a. & 9 & 11,78 & 2,52 \\
\hline Morck & 71 & $6 a$. & 32 & $5 a$. & 7 & 10,14 & 2,22 \\
\hline Berger & 53 & $7 a$. & 22 & 8a. & 11 & 4,82 & 2,41 \\
\hline Fama & 46 & $8 \mathrm{a}$. & 36 & $7 a$. & 9 & 5,11 & 1,28 \\
\hline Harris & 41 & $9 a$. & 16 & $9 a$. & 6 & 6,83 & 2,56 \\
\hline DeAngelo & 27 & 10a. & 22 & $8 \mathrm{a}$. & 10 & 2,70 & 1,23 \\
\hline
\end{tabular}

13 Fonte: dados da pesquisa. 
A segunda posição em citação difere da posição em quantidade de referências, onde ficou na quarta posição, que é de autoria de Shleifer (1986; 1997; 2002), o qual não publicou pesquisas individuais, somente em parceria - Shleifer \& Vishny (1986; 1997); Shleifer \& Wolfenzon (2002). Como co-autor as mais relevantes foram publicadas com La Porta, Lopez-de-Silanes, Shleifer \& Vishny (1997; 1998). A obra de destaque foi Shleifer \& Vishny (1986), com 21 ocorrências, sob o título de Large shareholders and corporate control. Este estudo versa sobre os temas shareholders, concentração e dispersão de propriedade; ganhos de capital e dividendos. Procuram responder a duas indagações principais: $\mathrm{O}$ quão forte são as forças que pressionam para uma crescente concentração de propriedade em uma empresa com propriedade dispersa? $\mathrm{E}$, por que os investidores corporativos e pessoais comumente preferem manter ações na mesma empresa, apesar de suas discrepantes preferências fiscais? Concluem que os acionistas minoritários e majoritários apresentam diferentes preferências em relação aos dividendos $e$ aos ganhos de capital. Enquanto os minoritários estão propensos a preferir ganhos de capital, os majoritários preferem dividendos.

$\mathrm{Na}$ segunda colocação entre as obras mais referenciadas tem-se La Porta. A obra com maior ocorrência, 18 observações, foi Corporate ownership around the world, publicada em 1999 e produzida com outros dois pesquisadores, Lopez-de-Silanes e Shleifer. Os autores usaram dados sobre estruturas de propriedade de grandes corporações em 27 economias ricas para identificar o acionista controlador final dessas empresas. Consideram que, exceto em economias com boa proteção aos acionistas, relativamente poucas empresas são amplamente sustentadas, em contraste com a imagem de separação e controle de propriedade de Berle \& Means (1932). Em vez disso, as empresas geralmente são controladas por famílias ou pelo Estado. O controle acionário pelas instituições financeiras é menos comum. Os acionistas controladores normalmente têm poder sobre as empresas, principalmente por meio de estrutura piramidal e participação na gestão.

A segunda obra, com 13 ocorrências, foi produzida juntamente com outros três autores, Lopez-de-Sila- nes, Shleifer e Vishny, publicada em 1998, intitulada de Law and finance. Contudo, não aborda o tema específico sobre estrutura de propriedade, e sim analisa as regras legais que abrangem a proteção aos acionistas e credores das empresas, a origem dessas regras, e a qualidade de sua aplicação em 49 países. Em relação à estrutura de propriedade, os autores concluem que a concentração da propriedade de ações das maiores empresas públicas é negativamente relacionada com a proteção ao investidor, consistentes com a hipótese de que os minoritários $e$ os acionistas diversificados são pouco importantes em países que não protegem os seus direitos.

No Figura 1 são apresentadas as referencias utilizadas nos 70 artigos publicados sobre o tema, com o respectivo ano de publicação. No Figura 5 observa-se que as referencias apresentaram o ano mínimo em 1776, com o clássico de Adam Smith (1776), intitulado The Wealth of Nations, e o máximo em 2011. Ocorreram picos nas quantidades de citações, sendo o primeiro em 1932, com o trabalho seminal de Berle \& Means (1932), The Modern Corporation and Private Property, Harcourt, Brace and World. Os 9 artigos citados neste ano referemse a essa obra.

O segundo pico ocorreu em 1976, com o clássico de Jensen \& Meckling (1976), o qual também compõe a amostra da pesquisa e citou a obra mais antiga da amostra, de autoria de Adam Smith (1776). Este clássico foi utilizado por Jensen \& Meckling (1976) para explicar os custos de agencia. Segundo os autores, a visão de caixa preta da empresa foi citada por Adam Smith e Marshall Alfred. Os autores utilizaram a visão de Smith (1776), de que os diretores de empresas (joint-stock company), sendo os gestores do dinheiro de outras pessoas, não se pode esperar que eles prestem atenção sobre o dinheiro com a mesma vigilância que os parceiros em copartnery privadas, que freqüentemente vigiam seus próprios recursos (Smith, 1776). Jensen \& Meckling (1976) argumentam que estes são os custos da separação de propriedade e controle, que Adam Smith propôs e Berle \& Means (1932) popularizaram 157 anos mais tarde.

A década de oitenta é a de maior representatividade na amostra, neste período ocorrem picos em anos 
Figura 5. Quantidade de referencias citadas nos artigos por ano de publicação ${ }^{14}$

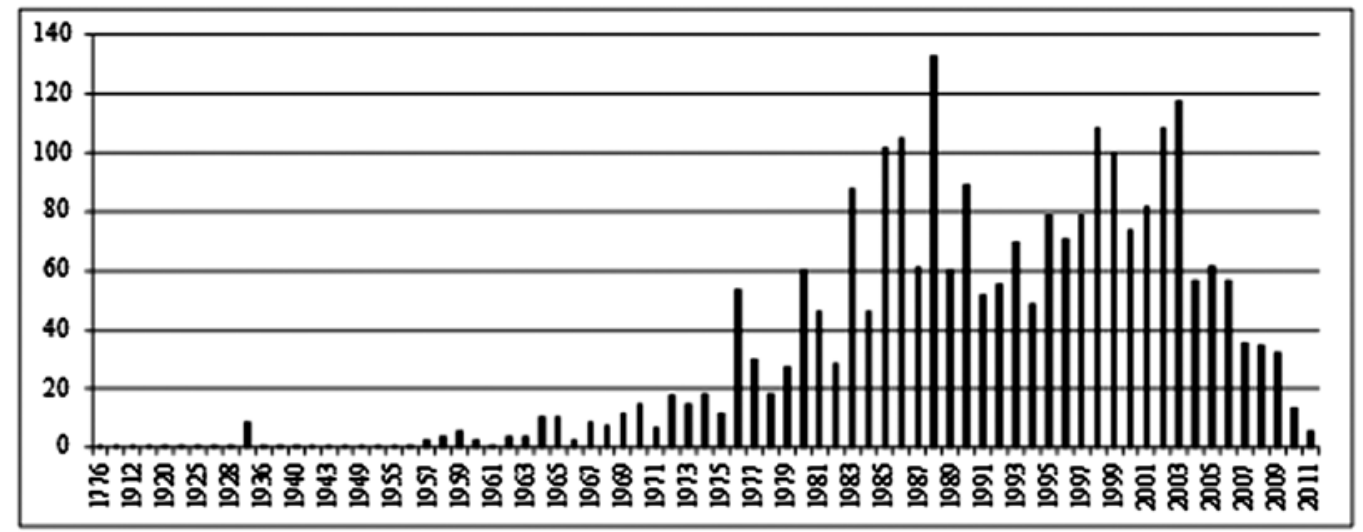

alternativos. Merecem destaque os anos de 1985, com 102 referências, 1986 com 105, e 1988, com 133, em cujo ano constatou-se o ponto máximo em citações. Em 1985, a literatura mais referenciada foi The structure of corporate ownership, de Demsetz \& Lehn (1985). Os autores argumentam que a estrutura de propriedade das empresas varia sistematicamente e é consistente com a maximização de valor. Observaram que a suposição de Berle and Means, em relação à concentração da propriedade e o lucro contábil do conjunto de empresas estudadas, não encontrou relação significativa. Shleifer \& Vishny (1986) se destacaram em referências com o trabalho Large shareholders and corporate control.

O ponto máximo em citações no período de análise ficou para o ano de 1988, com o trabalho Management ownership and market valuation: an empirical analysis, de Morck, Shleifer \& Vishny (1988). Estes autores avaliaram a relação entre a concentração das ações em posse dos administradores (altos executivos e conselheiros de administração) e o valor de mercado das empresas. Os autores testaram, de forma empírica, as preposições de custos de agencia e convergencia de interesses preconizadas por Jensen \& Meckling (1976) no desenvolvimento da teoria da estrutura de propriedade. O terceiro pico ocorreu no final da década de noventa até 2003, mantendo picos alternados entre 100 até 118 citações.

\section{Considerações finais}

Este estudo objetivou identificar redes sociais em teoria da estrutura de propriedade nos artigos publicados em periódicos internacionais de alto impacto. Pesquisa sociométrica, com metodologia empíricoanalítica, foi realizada em 11 periódicos internacionais de alto impacto da área de Administração. Para a seleção dos artigos filtrou-se a expressão "Ownership Structure" no título do periódico, em que retornaram 70 artigos. Utilizaram-se as técnicas de análise de bibliometria e análise de redes para comparar as principais características de redes sob o enfoque de small worlds e graus de centralidade.

Os resultados da pesquisa mostram que o número de artigos publicados $e$ a densidade das redes de cooperação vêm se ampliando no transcorrer das quatro décadas investigadas, o que salienta uma evolução no campo. Todavia, o número de artigos é baixo e a estrutura das redes é fragmentada se comparado a estudos realizados sobre outros temas, como Walter \& Silva (2008); Rocha, Walter, Silva \& Gimenez (2011), mas similar aos estudos de Fernandes, Dal Vesco \& Walter (2011). Talvez esse resultado também esteja relacionado ao foco do artigo consistir em um tema específico; devido a base de busca limitar-se ao termo "Ownership Structure" no título; e também à base de dados das publicações in-

14 Fonte: dados da pesquisa. 
ternacionais classificadas com índice de alto impacto JCR pela ISI 2009.

Em relação à baixa densidade das redes de coautoria, observa-se que os autores de estrutura de propriedade dão preferência a publicações em díades. Tem-se ainda que os autores possuem poucos artigos publicados sobre o tema, ou seja, os pesquisadores publicam esporadicamente. Contudo, pela análise das citações na base de dados da ISI, observa-se o impacto da produção. Esse resultado pode indicar que a teoria da estrutura de propriedade proposta por Jensen \& Meckling (1976) teve alto impacto na produção cientifica, caracterizando-o como um tema de pesquisa permanente para os pesquisadores.

No entanto observando-se temas específicos, tais como abordagem comportamental e social, essa característica pode ser crítica. Para o desenvolvimento do conhecimento da teoria, nestes casos seria importante que os pesquisadores desenvolvessem vários estudos com diferentes abordagens. Isso possibilitaria seu amadurecimento como pesquisadores em linhas relacionadas à área, bem como o contato com outros pesquisadores, estimulando a realização de parcerias.

Com base nos resultados da pesquisa, conclui-se que a produção científica internacional em estrutura de propriedade vem se desenvolvendo nas áreas de administração e contabilidade. Porém, necessita de investimentos no número de artigos, pois ao longo de quatro décadas somente foram encontradas 70 publicações em periódicos com JCR, o que poderia contribuir na densidade de suas relações. Um fator positivo encontrado centra-se na quantidade de citações de impacto. Por exemplo, Jensen \& Meckling (1976) obtiveram 6.479 citações só na base de dados da ISI. Este aspecto caracteriza a consolidação do tema como um campo de pesquisa permanente para os pesquisadores.

Os achados da pesquisa podem contribuir para o desenvolvimento da produção científica em estrutura de propriedade, por mensurar aspectos importantes de sua configuração, como o fato de os autores publicarem esporadicamente sobre o tema, bem como o de analisar os impactos dos artigos publicados em número de citações e temas. Como limitação desta pesquisa, destaca-se que o pequeno número de artigos sobre estrutura de propriedade, devido a busca no título e em periódicos de alto impacto, pode ter influenciado a baixa densidade encontrada nas redes e o pequeno número de artigos publicados por autor.

Recomenda-se para futuras pesquisas sobre o tema, ampliar o número de artigos analisados, incluindo um comparativo com a produção em países da América Latina publicada em periódicos. Poder-seia ainda analisar os artigos por meio de uma classificação das abordagens de pesquisa e dos paradigmas propostos por Burrel \& Morgan (2003), a fim de identificar outras tendências nas publicações do campo e suas lacunas estruturais. Sugere-se ainda investigar em que medida o board interlocking contribui, a partir da formação de redes corporativas $e$ pessoais, para a criação de fluxos de recursos essenciais à empresa.

\section{Referências}

Alchian, A. A. (1965)The basis of some recent advances in the Theory of Management of the Firm. Journal of Industrial Economics, 30-44.

Ang, J.S., Cole, R.A., \& Lin, J.W. (2000) Agency costs and ownership structure. Journal of Finance, 55, 81-107.

Baiman, S. (1982) Agency research in managerial accounting: a survey. Journal of Accounting Literature, 154-213.

Baiman, S. (1990) Agency research in managerial accounting: a second look. Accounting Organizations and Society, 15(4), $341-371$.

Bardin, L. (2002) Análise de conteúdo. Lisboa: Edições 70.

Berle, A., \& Means, G. (1932) The modern corporation\& private property. Hartcourt: Brace \& World.

Bonner, S. E., Hesford, J. W., Van Der Stede, W. A., \& Young, S. M. (2006) The most influential journals in academic accounting. Accounting, Organizations and Society, 31(7), 663-685.

Brickley, J.A., Lease, R.C., \& Smith, C.W. (1988) Ownershipstructure and voting on antitakeover amendments. Journal of Financial Economics, 20, 267-291.

Brickley, J. A., Coles, J. L., \& Terry, R. L. (1994)The board of directors and the enactment of poison pills. Journal of Financial Economics, 35, 371-390.

Burrell, G. \& Morgan, G. (2003) Sociological paradigms and organisational analysis. Vermont/USA: Ashgate Publishing Company.

Burt, R. (1980) Models of network structure. Annual Review of Sociology, 6, 79-141

Burt, R. S. (1992) The social structure of competition. En: BURT, R. S. Structural holes: the social structure of competition. Cambridge: Harvard University Press. pp. 8-49.

Chaganti, R. \& Damanpour, F. (1991) Institutional ownership, capital structure, and firm performance. Strategic Management Journal, 12(7), 479-491. 
Cooper, D. J. (1983) Tidiness, muddle, and things: commonalities and divergencies in two approaches to management accounting research. Accounting, Organizations and Society, 8(2/3), 269-286.

Cotter, J., Shivdasani, A., \& Zenner, M. (1997) Do independent directors enhance target shareholder wealth during tender offers? Journal of Financial Economics, 43, 195-218.

Covaleski, M. A., Dirsmith, M. W., \& Samuel, S. (1996) Managerial accounting research: the contributions of organizational and sociological theories. Journal of Management Accounting Research, 8, 1-35.

Creswell, J. W. (1994) Research design: qualitative \& quantitative approaches. Thousand Oaks: Sage.

Dal Vesco, D. G., Machado, D. G., \& Scarpin, J. E. (2010) Cooperação entre os capitais sociais em empresas Concessionárias de Serviços Públicos no Brasil: evidências estruturais em concessões de rodovias. En: EnANPAD, 34., 2010, Rio de Janeiro. Anais. Rio de Janeiro: ANPAD.

Damodaran, A. (2002) Finanças corporativas aplicadas: manual do usuário. Trad. Jorge Ritter. Porto Alegre. Bookman.

Demsetz, H. \& Lehn, K. (1985) The structure of corporate ownership: causes and consequences. Journal of Political Economy, 93(6), 1155-1177.

Denis, D.J., Denis, D.K. \& Sarin, A. (1997) Ownership structure and top executive turnover. Journal of Financial Economics, 45, 193-221.

Denis, D.K. \& McConnell, J.J. (2003) International Corporate Governance. Journal of Financial and Quantitative Analysis, forthcoming, 38, 1-36.

Fama, E.F. (1980) Agency problems and the theory of the firm. Journal of Political Economy, 88, 288-307.

Fama, E.F. \& Jensen, M.C. (1983) Separation of ownership and control. Journal of Law and Economics, 26, 301-325.

Fan, J. P. \& Wong, T.J. (2002) Corporate ownership structure and the informativeness of accounting earnings in East Asia. Journal of Accounting and Economics, 33, 401-425.

Fernandes, F. C., Dal Vesco, D. G. \& Walter, S. A. (2011) Redes sociais em teoria da decisão: uma análise do campo das produções cientificas nacionais. En: SIMPOI, São Paulo. Anais. São Paulo: FGV.

Galaskiewcz, J. \& Wasserman, S. (1994) Advances in social network analysis: research in the social and behavioral sciences. London: Sage.

Galbraith, J. K. (1967) The new industrial state. Boston: Houghton Mifflin.

Geeraets, G. (1984) The effect of ownership on the organization structure in small firms. Administrative Science Quarterly, 29, 232-237.

Granovetter, M. (1973) The strength of weak ties. American Journal of Sociology, 78(6), 1360-1380.

Herman, E. S. (1981) Corporate control, corporate power. New York: Cambridge University Press.

Hesford, J. W., Sam Lee, S.H., Van Der Stede, W. A. \& Young, S. M. (2007) Management accounting: a bibliographic study. En: Chapman, C. S., Hopwood, A. G., \& Shields, M. D. Handbook of management accounting research. Oxford: Elsevier.

Hopwood, A. G. (1978)Towards an organizational perspective for the study of accounting and information systems. Accounting, Organizations and Society, 3(1), 3-13.
Hopwood, A. G. (1979) Editorial Accounting, Organizations and Society, 4(3), 145-147.

Hopwood, A. G. (1983) On trying to study accounting in the contexts in which it operates. Accounting, Organizations and Society, 8(2/3), 287-305.

lannota, G., Giacomo, N., \& Sironi, A. (2007) Ownershipstructure, risk and performance in the European banking industry. Journal of Banking and Finance, 31, 2127-2149.

Jackson, M. O. \& Wolinsky, A. (1996)A strategic model of social and economic networks. Journal of Economic Theory, 7, 44-74.

Jensen, M. C. (1969) Risk, the pricing of capital assets, and the evaluation of investmentportfolios. Journal of Business, 42(2), 167-247.

Jensen, M.C. (1979) Tests of capital market theory and implications of the evidence. Boston, MA: Handbook of Financial Economics.

Jensen, M.C. (1986) Agency costs of free cash flow, corporate finance, and takeovers. The American Economic Review, 76, 323-329.

Jensen, M.C. (1993) The modern industrial revolution, exit and the failure of internal control systems. Journal of Finance, 48, 831-880.

Jensen, M. C. \& Meckling, W. H. (1976)Theory and the Firm: Managerial Behavior, Agency Costs and Ownership Structure. Financial Econ., 305-360.

Jensen, M.C. \& Murphy, K.J. (1990a) Performance pay and top management incentives. Journal of Political Economy, 98, 225-264.

Jensen, M.C. \& Murphy, K.J., (1990b) CEO incentives: It's not how much you pay, but how. Journal of Applied Corporate Finance, 3(3), 36-49.

Jensen, M.C. \& Ruback, R.S. (1983)The market for corporate control. Journal of Financial Economics, 11, 5-50.

Jensen, M.C. \& Warner, J.B. (1988)The distribution of power among corporate mangers, shareholders, and directors. Journal of Financial Economics, 20, 3-24.

Johnson, H. T. \& Kaplan, R. S. (1987) Relevance lost: the rise and fall of management accounting. Boston, MA: Harvard Business School Press.

Kaplan, R. S. (1983) Measuring manufacturing performance: a new challenge for management accounting research. The Accounting Review, 58(4), 686-705.

Kaplan, R. S. (1984) The evolution of management accounting. The Accounting Review, 59(3), 390-418.

Kaplan, R. S. (1986) The role for empirical research in management accounting. Accounting, Organizations and Society, 11(4/5), 429-452.

Kaplan, R. S. (1993) Research opportunities in management accounting. Journal of Management Accounting Research, 5, 1-14.

Katz, S.P. (2009) Earnings quality and ownership structure: the role of private equity sponsors. The Accounting Review, 84(3), 623-658

La Porta, R., Lopez-de-Silanes, F. \& Shleifer, A. (1999) Corporate ownership around the world. Journal of Finance, 54, 471-517

La Porta, R., Lopez-de-Silanes, F., Shleifer, A. \& Vishny, R.W. (1997) Legal determinants of external finance. Journal of Finance, 52, 1131-1150.

La Porta, R., Lopez-de-Silanes, F., Shleifer, A. \& Vishny, R.W. (1998) Law and finance. Journal of Political Economy, 106, 1113-1155.

Larner, P. (1971) Management control and the large corporation. New York: Dunellen. 
Lazzarini, S. G. (2007) Mudar tudo para não mudar nada: análise da dinâmica de redes de proprietários no Brasil como "mundos pequenos". RAE-eletrônica, 6(1), Art. 6.

Lemmon, M.L. \& Lins, K.V. (2003) Ownership structure, corporate governance, and firm value: Evidence from the East Asian financial crisis. Journal of Finance, 58(4), 1445-1468.

Leuz, C, D. (2006) Cross-listing, bonding, and firms' reporting incentives: a discussion of Lang, Raedy, and Wilsom (2006). Journal of Accounting and Economics, 42, 285-299.

Liu, X., Bollen, J. N., Michael, L. \& Van De Sompel, H. (2005) Coauthorship networks in the digital library research community. Information Processing \& Management. 41, 1462-1480.

Macias-Chapula, C. A. (1998) O papel da informetria e da cienciometria e sua perspectiva nacional e international. Ciência da Informação, 27(2), 134-140.

Macintosh, N. B. \& Scapens, R. W. (1990) Structuration theory in management accounting. Accounting, Organizations and Society, 15(5), 455-477.

Malatesta, P.H. \& Walkling, R.A. (1988) Poison pill securities - stockholder wealth, profitability, and ownership structure.Journal Of Financial Economics, 20(1/2), 347-376.

Mayers, D., Shivdasani, A. \& Smith Jr, C. W. (1997) Board composition and corporate control: evidence from the insurance industry. Journal. Of business, 70(1), 33-62.

McEachern, W. A. (1975) Managerial control and performance. Lexington, MA: Lexington Books.

Meckling, W. H. (1976) Values and the choice of the model of the individual in the socialsciences. Swiss Journal of Economics and Statistics, 112(4), 545-560.

Mehran, H. (1995) Executive-compensation structure, ownership, and firm performance. Journal of Financial Economics, 38(2), 163-184.

Mendes-da-Silva, W. (2010) Board interlocking, desempenho financeiro e valor das empresa brasileiras listadas em bolsa: analise sob a ótica da teoria dos grafos e de redes socais. 254 f. Tese (Doutorado em Administração) - Universidade de São Paulo, São Paulo.

Morck, R., Shleifer, A. \& Vishny, R.W. (1988) Management ownership and market valuation: an empirical analysis. Journal of Financial Economics, 20, 293-315.

Palmer, D., Friedland, R., Jennings, P.D. \& Powers, M. E. (1987) The economics and politics of structure: the multidivisional firm and the large U.S. corporation. Administrative Science Quarterly, 32, 25-48.

Rocha, D. T., Walter, S. A., Silva, E. D. \& Gimenez,F. A. P. (2011) Processo de formação de estratégia em pequenas empresas: um estudo bibliométrico e sociométrico. Revista da micro e pequena empresa (FACCAMP), 5, 101-118.

Rossoni, L. \& Graeml A. L. A. (2009) Influência da imersão institucional e regional na cooperação entre pesquisadores do campo da Administração da Informação do Brasil. En: EnADI, Curitiba. Anais. Rio de Janeiro: ANPAD.

Rossoni, L. \& Guarido, E. R. Filho (2009) Cooperação entre programas de pós-graduação em administração no Brasil: evidências estruturais em quatro áreas temáticas. Revista de Administração Contemporânea, 13(3), 366-390.

Salancik, G. R. \& Pfeffer, J. (1980) Effects of ownership and performance on executive tenure in U.S. corporations. Academy of Management Journal, 23, 653-664.

Sampieri, R. H., Collado, C. F. \& Lucio P. B. (2006) Metodologia de pesquisa. São Paulo: McGraw-Hill, 3. ed.

Saunders A., Strock, E. \& Travlos, N.G. (1990) Ownership structure, deregulation, and bank risk-taking. Journal Of Finance, 45(2), 643-654.

Shivdasani, A. (1993) Board composition, ownership structure, and hostile takeovers. Journal of Accounting \& Economics, 16(1/3), 167-198.

Shleifer, A. \& Vishny, R. (1986) Large shareholders and corporate control. Journal of Political Economy, 94, 461-488

Shleifer, A. \& Vishny. R. W. (1997) A survey of corporate governance. Journal of Finance, 52, 737-783.

Shleifer, A. \& Wolfenzon, D. (2002) Investor Protection and Equity Markets. Journal of Financial Economics, 66(1), 3-27.

Smith, A. (1776) The wealth of nations. Edited by Edwin Cannan, 1904. Reprint edition 1937. New York, Modern Library.

Sorensen, R. L. (1974) The separation of ownership and control and firm performance: an empirical analysis. Southern Economic Journal, 41, 145-148.

Veblen, T. (1924) The engineers and the price system. New York: Viking.

Walter, S. A. \& Silva, E. D. (2008) Visão baseada em recursos: um estudo bibliométrico e de redes sociais da produção científica da área de estratégia do EnANPAD 1997-2007. En: EnANPAD, 32, Anais. Rio de Janeiro: ANPAD, 2008.

Watts, D. \& Strogatz, S. (1998) Collective dynamics of 'small world' networks. Nature, 393(6684), 440-442.

Weisbach, M. S. (1988) Outside directors and CEO turnover. Journal of Financial Economics, 20, 431-460.

Young, S. M. \& Selto, F. H. (1991) New manufacturing practices and cost management: a review of the literature and directions for future research. Journal of Accounting Literature, 10, 265-298. 